\title{
Using Estimated On-Site Ambient Temperature Has Uncertain Benefit When Estimating Postmortem Interval
}

\author{
Laurent Dourel, Thierry Pasquerault, Emmanuel Gaudry, and Benoît Vincent \\ Département Entomologie, Institut de Recherche Criminelle de la Gendarmerie Nationale, 1 Boulevard Théophile Sueur, \\ 93111 Rosny-Sous-Bois Cedex, France \\ Correspondence should be addressed to Laurent Dourel, etm.ircgn@gendarmerie.interieur.gouv.fr
}

Received 4 September 2009; Accepted 21 March 2010

Academic Editor: David Denlinger

Copyright ( $\odot 2010$ Laurent Dourel et al. This is an open access article distributed under the Creative Commons Attribution License, which permits unrestricted use, distribution, and reproduction in any medium, provided the original work is properly cited.

\begin{abstract}
The forensic entomologist uses weather station data as part of the calculation when estimating the postmortem interval (PMI). To reduce the potential inaccuracies of this method caused by the distance between the crime scene and the meteorological station, temperature correlation data from the site of the corpse may be used. This experiment simulated the impact of retrospective weather data correction using linear regression between seven stations and sites in three climatic exposure groups during three different seasons as part of the accumulated degree days calculation for three necrophagous species (Diptera: Calliphoridae). No consistent benefit in the use of correlation or the original data from the meteorological stations was observed. In nine cases out of 12 , the data from the weather station network limited the risk of a deviation from reality. The forensic entomologist should be cautious when using this correlation model.
\end{abstract}

\section{Introduction}

Knowledge of the postmortem interval (PMI) is of crucial importance in criminal investigations. When the limits of traditional legal medicine are reached for putrefied corpses colonized by insects, forensic entomology can provide the only means for estimating the time since death, often calculated with the thermal summation model [1]. The identification of necrophagous fauna collected on the cadaver [2] and its surroundings, together with analysis of reliable environmental data from the crime scene, enables the entomologist to determine the age of the immature insects and, consequently, estimation of the PMI [3-5]. However, there could be a delay between death and initial insect laying on the body caused by burial, freezing, or confinement in a sealed place, for example.

When insects are used for intelligence or evidential purposes in criminal investigations [6], it is important to assess the factors required for their growth and development. Environmental conditions and climatic parameters, mainly temperature, have an impact on the rate of tissue decay [7] and affect the adult behaviour, larval development, and insect succession rate $[8,9]$. Therefore knowledge of the microclimates under which insects develop on a body is fundamental to forensic entomology [5].

More often than not, the crime scene is located some distance away from the nearest weather station. Therefore, the microclimates experienced at the two locations will differ from each other, and the temperature data will not be directly comparable $[6,10]$. These differences may affect the PMI calculation. Among 725 cases treated by the entomology department of the Forensic Science Institute of the French Gendarmerie [11, 12] between 1992 and 2007, $80.5 \%$ required accurate studies of climatic data. These cases were general when the corpse was situated outdoors or inside a location which was open to the elements. The other cases dealt with body discovery indoors, where other variables had to be considered such as heating systems, openings, and others parameters which might influence the prevailing conditions.

One of the solutions proposed by forensic entomologists is the use of a correction factor, which is calculated by comparing the data collected from the weather station with the body deposition site for some days after the corpse 
has been recovered [7, 13-17]. However, limitations of this method have to be considered. Archer [18], through the use of temperatures correlations between six hypothetical body discovery sites and a single weather station, emphasized the difficulty in the application of retrospective regression when the climatic patterns differ greatly from those that occurred while the body was still in situ.

The following series of experiments introduce the limits of the linear regression method in its application to judiciary casework. The present paper measures the impact, expressed in insect time development, of weather data corrections in different environmental conditions and different correlation durations.

\section{Material and Methods}

2.1. Location of Experiments. Three groups (exposed, partially protected, and protected) were defined according to their climatic exposure to the following criteria: direct radiance, precipitations, wind, and dew. Some of the characteristics of these three groups are illustrated in Figure 1. Seven sites were chosen based on these exposure groups. The experimental period was spread out across several different seasons for a number of the sites (Table 1).

2.2. Collection of Ambient Temperature Data. Ambient temperature data were recorded with one Testo 175-T1 data logger per site (Table 1). These waterproof data loggers measure temperatures from $-35^{\circ} \mathrm{C}$ to $+70^{\circ} \mathrm{C}$ with a resolution of $0.1^{\circ} \mathrm{C}$ and an accuracy of $\pm 0.5^{\circ} \mathrm{C}$. All of the data loggers were calibrated with a standard thermometer before the experiment. The relative error was measured at $0.07 \%$ to $0.24 \%$ before the experiment and $0.32 \%$ to $0.70 \%$ after. This deviation was due to the natural drift of the equipment with time. The data loggers were set to record at three hour intervals, to assure a sufficient range (some of them stayed several months on the sites), with a start time of midnight, which was synchronized with the Météo France station. The data loggers were placed between 0.2 and 1.50 meters in height from the ground. The data were subsequently analysed with Testo Comsoft software.

Weather data were obtained from the French national meteorology office, Météo France, which has 3725 weather stations throughout the French metropolitan territory. The Météo France temperature data are recorded with international Norma (World Meteorological Organization), which means that it is recorded under sheltered conditions at 1.5 meters in height with grassland surroundings. There was no significant difference in altitude between the locations of the data loggers and the weather stations.

2.3. Selection of Fly Species. Three species of fly (DipteraCalliphoridae), which are known to colonize corpses soon after death $[1,3]$ were selected according to their frequency among 725 forensic caseworks carried out by the department and their developmental threshold (low, middle, and high value-Table 2) [1, 19]. Calliphora vicina RobineauDesvoidy was encountered in $33 \%$ of cases. It is a common species of fly widely distributed throughout the Holarctic region and reputed to be a very common urban species. Adults are attracted to faeces, decaying meat, and fruit whereas the larvae develop in carrion. Lucilia sericata (Meigen), present in $15.6 \%$ of the cases, is widespread throughout the major zoogeographical regions. Adults are attracted by carrion, open wounds, and faeces. The larvae can complete their development in all of these substrates. Finally, Protophormia terraenovae (Robineau-Desvoidy) encountered in $8 \%$ of cases has a Holarctic distribution. It is most common in spring and in summer where higher temperatures occur. The larvae develop in carrion.

2.4. Simulations from Retrospective Correlations. For each site the period of study was 40 days. At sites S2 and S7, three different times of the year were chosen and two different times of year were selected for site S6 (Table 3).

The temperatures shown in the table correspond to the following:

(i) the daily average of temperature minima and maxima from Météo France data,

(ii) the daily average of the temperatures recorded every three hours by the data loggers.

The day of cadaver discovery was termed $D=0$. From $D=0$, a linear regression curve was calculated between the temperature data from the data loggers $\left(T_{d}\right)$ and from the Météo France station $\left(T_{\mathrm{ws}}\right)$ for three different durations: 5 , 10 , and 15 days $\left(C_{5}, C_{10}\right.$, and $\left.C_{15}\right)$ (Figure 2). The selection of the three durations has to be considered as a simulation (from $D=0$ ) for a way to build a more representative working model for the PMI calculation in real casework and its judicial constraints (time limits, costs, and availability of data).

For 25 days before $D=0$, we applied the linear regressions on $T_{\mathrm{ws}}$. We obtained an estimation of temperatures $\left(T_{\text {est }}\right)$ for $C_{5}, C_{10}$, and $C_{15}$ (Figure 2). Then the summation of the difference between $T_{d}$ and $T_{\mathrm{ws}}$ for a period of 25 days was calculated:

$$
\sum\left(T_{d}-T_{\mathrm{ws}}\right) .
$$

The same calculation was done between $T_{d}$ and each $T_{\text {est }}$ obtained for the 25 days:

$$
\sum\left(T_{d}-T_{\text {est }}\right) .
$$

The choice of time period for correlation calculations overlapped imposes a direct comparison between $T_{\text {est }}$ (with $C_{5}, C_{10}$, or $C_{15}$ ) and $T_{d}$ and/or $T_{\mathrm{ws}}$ and not between $T_{\text {est }}$ themselves.

2.5. Insect Development. In forensic entomology, the PMI estimation is based on the study of the duration of insect development. There is a direct relationship between time of development and the ambient temperatures experienced by the insect. Marchenko [19] reported that the development of insects could be described using temperature summation, that is, the accumulated degree day (ADD) model. 

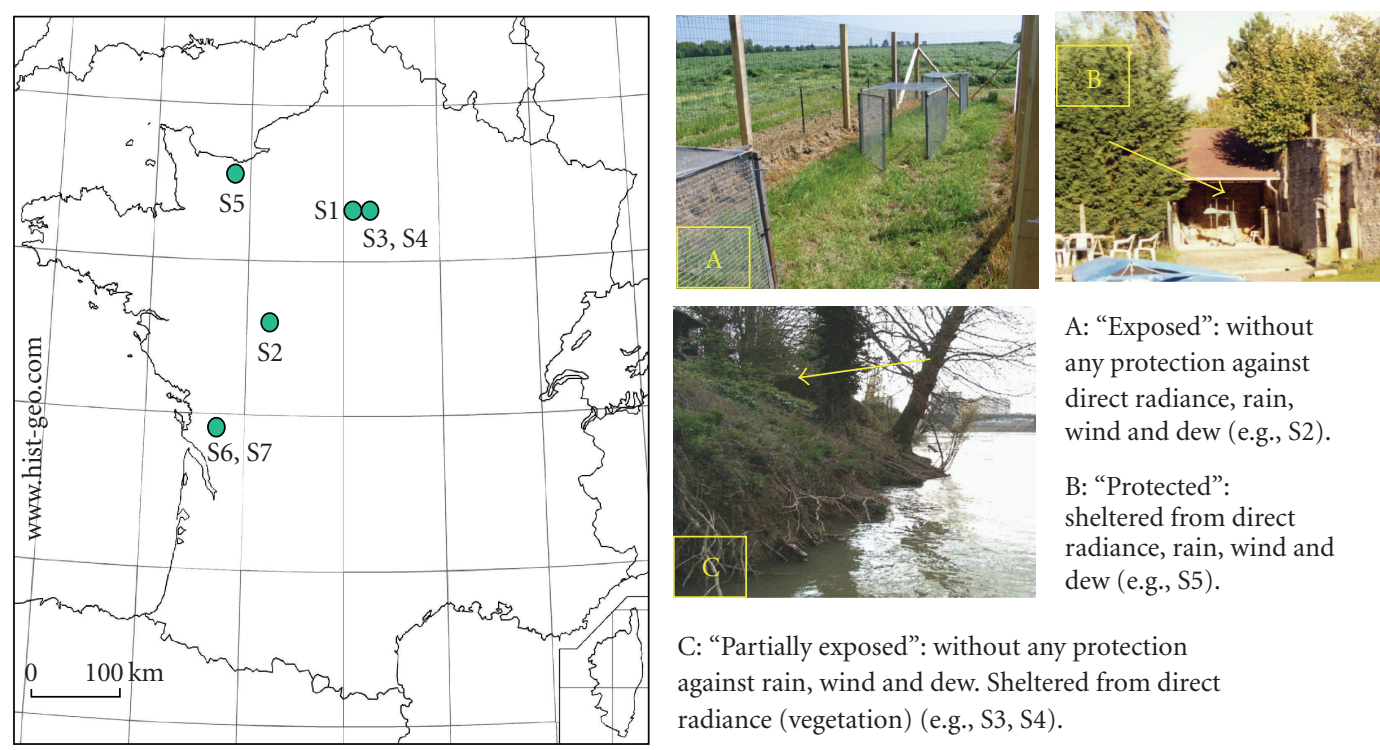

A: "Exposed": without any protection against direct radiance, rain, wind and dew (e.g., S2).

B: "Protected": sheltered from direct radiance, rain, wind and dew (e.g., S5).

C: "Partially exposed": without any protection against rain, wind and dew. Sheltered from direct radiance (vegetation) (e.g., S3, S4).

FIgURE 1: Location and general characteristics of the sites.

TABLE 1: Characteristics of the sites and data loggers' climatic exposure; comparison with their meteorological station associated (A, B, or C: periods of experimentation for a same spot).

\begin{tabular}{|c|c|c|c|c|c|}
\hline Spot (s) & Period of experiment & Town/Characteristic of location (S) & $\begin{array}{l}\text { Data loggers } \\
\text { climatic } \\
\text { exposure }\end{array}$ & $\begin{array}{l}\text { Distance } \\
\text { Meteorological } \\
\text { station (MS)_-S }\end{array}$ & $\begin{array}{l}\text { Altitude } \\
\text { MS/(Altitude } \\
\text { MS-Altitude S) }\end{array}$ \\
\hline S1 & $\begin{array}{l}03 / 10 / 2002 \text { to } \\
11 / 11 / 2002\end{array}$ & Rosny sous Bois/On lawn & exposed & $0.03 \mathrm{~km}$ & $112 \mathrm{~m} / 0 \mathrm{~m}$ \\
\hline \multirow[t]{2}{*}{ S2 $(A, B, C)$} & $\begin{array}{l}\text { A: } 13 / 05 / 2004 \text { to } \\
21 / 06 / 2004 \\
\text { B: } 27 / 09 / 2004 \text { to } \\
05 / 11 / 2004\end{array}$ & \multirow[t]{2}{*}{ Nouzilly/Fallow field—on the ground } & \multirow[t]{2}{*}{ exposed } & \multirow[t]{2}{*}{$15.10 \mathrm{~km}$} & \multirow[t]{2}{*}{$148 \mathrm{~m} /-2 \mathrm{~m}$} \\
\hline & $\begin{array}{l}\text { C: } 04 / 03 / 2005 \text { to } \\
12 / 04 / 2005\end{array}$ & & & & \\
\hline S3 & $\begin{array}{l}03 / 10 / 2002 \text { to } \\
11 / 11 / 2002\end{array}$ & $\begin{array}{l}\text { Joinville Le Pont/Under cover of } \\
\text { vegetation }\end{array}$ & $\begin{array}{l}\text { partially } \\
\text { protected }\end{array}$ & $0.20 \mathrm{~km}$ & $37 \mathrm{~m} / 0 \mathrm{~m}$ \\
\hline S4 & $\begin{array}{l}03 / 10 / 2002 \text { to } \\
11 / 11 / 2002\end{array}$ & $\begin{array}{l}\text { Joinville Le Pont/Banks of Marne } \\
\text { river-Under cover of vegetation }-1.8 \mathrm{~m} \\
\text { from the river }\end{array}$ & $\begin{array}{l}\text { partially } \\
\text { protected }\end{array}$ & $0.20 \mathrm{~km}$ & $37 \mathrm{~m} / 0 \mathrm{~m}$ \\
\hline S5 & $\begin{array}{l}15 / 04 / 2004 \text { to } \\
24 / 05 / 2004\end{array}$ & $\begin{array}{l}\text { Cairon/Stone shelter with roof in tile } \\
-30 \mathrm{~m}^{2} \text { - totally open on its South façade }\end{array}$ & protected & $6.60 \mathrm{~km}$ & $62 \mathrm{~m} / 26 \mathrm{~m}$ \\
\hline S6 (A, B) & $\begin{array}{l}\text { A: } 20 / 04 / 2004 \text { to } \\
29 / 05 / 2004 \\
\text { B: } 22 / 07 / 2004 \text { to } \\
30 / 08 / 2004\end{array}$ & $\begin{array}{l}\text { Fontenet/Breeze block shelter with roof } \\
\text { in cement }-2 \mathrm{~m}^{2} \text {-Partially open-Facing } \\
\text { West }\end{array}$ & protected & $12.20 \mathrm{~km}$ & $148 \mathrm{~m} /-2 \mathrm{~m}$ \\
\hline \multirow[t]{2}{*}{ S7 $(\mathrm{A}, \mathrm{B}, \mathrm{C})$} & $\begin{array}{l}\text { A: } 28 / 08 / 2005 \text { to } \\
06 / 10 / 2005 \\
\text { B: } 28 / 03 / 2006 \text { to } \\
06 / 05 / 2006\end{array}$ & \multirow[t]{2}{*}{$\begin{array}{l}\text { Fontenet/Breeze block shelter with roof } \\
\text { in corrugated iron roof }-2 \mathrm{~m}^{2} \text { - totally } \\
\text { open on its North East façade }\end{array}$} & \multirow[t]{2}{*}{ protected } & \multirow[t]{2}{*}{$12.20 \mathrm{~km}$} & \multirow[t]{2}{*}{$148 \mathrm{~m} /-2 \mathrm{~m}$} \\
\hline & $\begin{array}{l}\text { C: } 08 / 06 / 2006 \text { to } \\
17 / 07 / 2006\end{array}$ & & & & \\
\hline
\end{tabular}




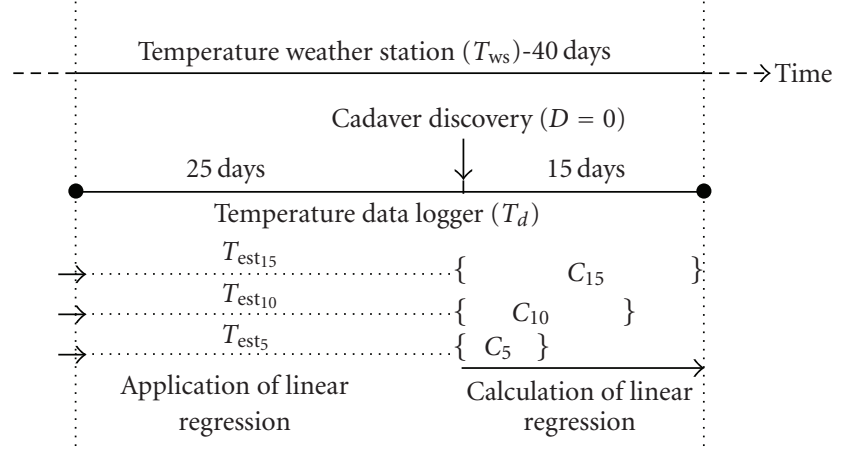

Figure 2: Calculation and application of linear regression.

TABLE 2: Thermal parameters $\left({ }^{\circ} \mathrm{C}\right)$ regulating development of flies. Data are from Marchenko [19] (ADD: accumulated degree day).

\begin{tabular}{lll}
\hline Species & $\begin{array}{l}\text { ADD from egg to } \\
\text { adult }\end{array}$ & $\begin{array}{l}\text { Minimum } \\
\text { development } \\
\text { threshold }\end{array}$ \\
\hline $\begin{array}{l}\text { Calliphora vicina } \text { R.-D. } \\
\text { Protophormia terraenovae } \\
\text { (R.-D.) }\end{array}$ & 388 & 2.0 \\
Lucilia sericata (M.) & 251 & 7.8 \\
\hline
\end{tabular}

To determine an estimate of the date of oviposition, the IRCGN Entomology department mainly utilises ADD model. Other published insect developmental data recorded under constant temperature conditions, as Kamal's work [8], are also used at the department in casework. The total ADD needed for insect development at one constant rearing temperature (ADDi) was calculated from the equation: ADDi $=n\left(T_{i}-T_{s}\right)$, with $n$ being the number of development days, $T_{i}$ the rearing temperature, and $T_{s}$ the development threshold. This estimation of ovipositions period is expressed as a time interval.

In this study, we used the ADD model for all of the data from the three species of Diptera. Zero was used to replace all of the temperature values recorded below the developmental threshold.

$T_{d}$, which is the temperature recorded at the site, was used as a reference. There were two ways to express the results.

(1) When the total temperature summation needed to complete development (with $T_{d}$ ) was not reached after 25 days, the total temperature summations were compared at 25 days.

(2) When the total temperature summation needed to complete development (with $T_{d}$ ) was reached before 25 days, the total temperature summations were compared at this date, which was the closest value required for total development.

Comparisons between ADD $T_{d}$ and the other ADD values obtained from $T_{\mathrm{ws}}$ and the correlations were produced in temperature format (degrees Celsius) and then transformed

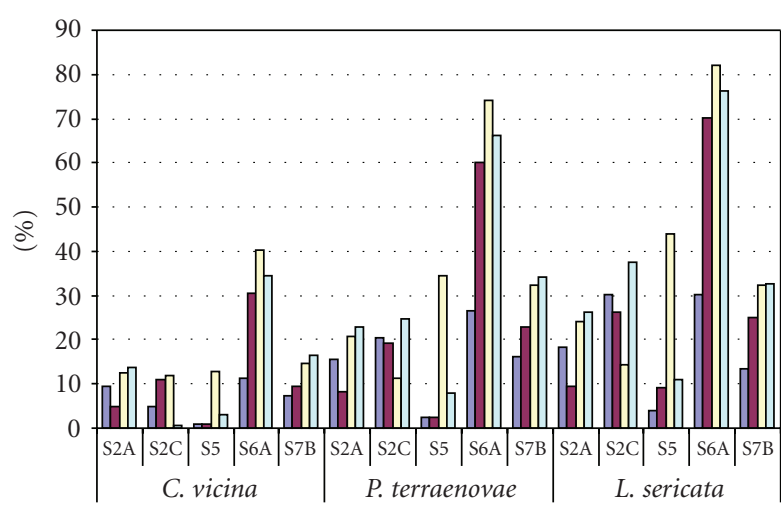

$$
\begin{aligned}
& \text { - } \mathrm{ADD} T_{d} \text { - } \mathrm{ADD} T_{\mathrm{ws}} \quad \text { ADD } T_{d} \text { - } \mathrm{ADD} T_{\text {est } 5} \\
& \text { 口 } \mathrm{ADD} T_{d} \text { - } \mathrm{ADD} T_{\text {est10 }} \quad \mathrm{ADD} T_{d} \text { - } \mathrm{ADD} T_{\text {est15 }}
\end{aligned}
$$

FIgure 3: Differences between ADD $T_{d}$ and ADD values using $T_{\mathrm{ws}}$ and correlations compared to ADD $T_{d}$, expressed as percentages $\left.\left(\left[\mathrm{ADDx}-\mathrm{ADD} T_{d}\right) / \mathrm{ADD} T_{d}\right] \times 100\right)$ for data registered in spring.

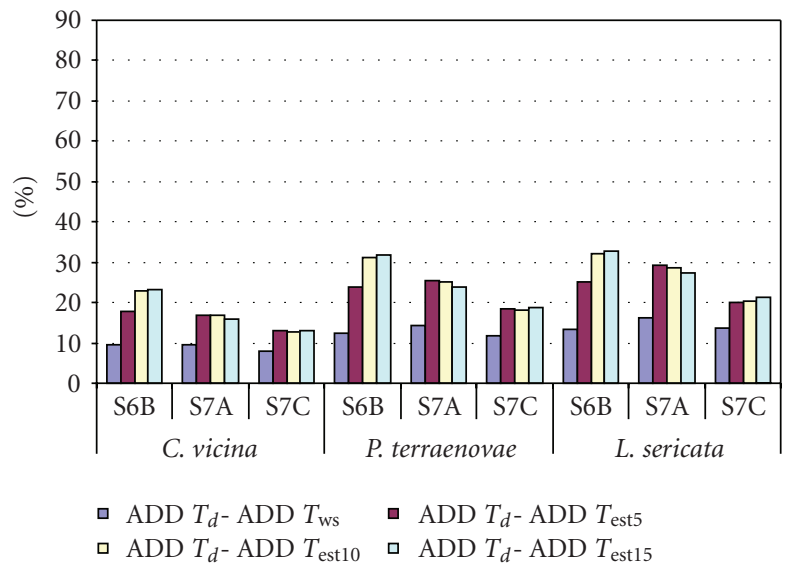

Figure 4: Differences between ADD $T_{d}$ and ADD values using $T_{\mathrm{ws}}$ and correlations compared to $\mathrm{ADD} T_{d}$, expressed as percentages $\left.\left(\left[\mathrm{ADDx}-\mathrm{ADD} T_{d}\right) / \mathrm{ADD} T_{d}\right] \times 100\right)$ for data registered in summer.

into percentage values for ease of understanding (Figures 3 , 4 , and 5).

\section{Results}

Results are shown in Table 3 and in Figures 3-5. Overall, there was no consistent benefit in the use of correlation or the original data from the meteorological stations. In 9 cases out of 12, the data obtained from Météo France stations are closer to the local situation $\left(T_{d}\right)$. In the three remaining cases, the best fitting results were obtained with $C_{5}$ or $C_{15}$.

For the sites under different climatic exposures, the best fitting temperature data originated from different sources. For S1, the most suitable temperature data was obtained with $C_{15}$ and with an ADD shorter no matter which species was considered. For S2, depending on the time of year and the species considered, it was difficult to determine the most 
TABLE 3: Summation of the difference between $T_{d}$ and others temperatures $\left({ }^{\circ} \mathrm{C}\right)$ data for 25 days.

\begin{tabular}{|c|c|c|c|c|c|c|}
\hline Spot & $D=0$ & Linear regression curve equation; $R^{2}$ & $\sum\left(T_{d}-T_{\mathrm{ws}}\right)$ & $\sum\left(T_{d}-T_{\text {est }}\right)$ & $\sum\left(T_{d}-T_{\mathrm{est}_{10}}\right)$ & $\sum\left(T_{d}-T_{\mathrm{est}_{15}}\right)$ \\
\hline \multirow{3}{*}{ S1 } & \multirow{3}{*}{$28 / 10 / 2002$} & $C_{5}: y=1.0172 x-0.4713 ; R^{2}=0.9068$ & \multirow{3}{*}{-16.16} & \multirow{3}{*}{-9.87} & \multirow{3}{*}{-14.28} & \multirow{3}{*}{4.67} \\
\hline & & $C_{10}: y=1.0682 x-0.9465 ; R^{2}=0.9149$ & & & & \\
\hline & & $C_{15}: y=0.841 x+1.199 ; R^{2}=0.8468$ & & & & \\
\hline \multirow{3}{*}{ S2 A } & \multirow{3}{*}{$07 / 06 / 2004$} & $C_{5}: y=0.6941 x+5.3294 ; R^{2}=0.5810$ & \multirow{3}{*}{34.60} & \multirow{3}{*}{17.82} & \multirow{3}{*}{45.63} & \multirow{3}{*}{50.12} \\
\hline & & $C_{10}: y=0.8332 x+2.0987 ; R^{2}=0.9067$ & & & & \\
\hline & & $C_{15}: y=0.8773 x+1.2475 ; R^{2}=0.9375$ & & & & \\
\hline \multirow{3}{*}{ S2 B } & \multirow{3}{*}{$22 / 10 / 2004$} & $C_{5}: y=0.9038 x+0.0263 ; R^{2}=0.9165$ & \multirow{3}{*}{11.70} & \multirow{3}{*}{41.92} & \multirow{3}{*}{35.11} & \multirow{3}{*}{36.20} \\
\hline & & $C_{10}: y=0.7369 x+2.4418 ; R^{2}=0.8691$ & & & & \\
\hline & & $C_{15}: y=07373 x+2.3932 ; R^{2}=0.897$ & & & & \\
\hline \multirow{3}{*}{ S2 C } & \multirow{3}{*}{$29 / 03 / 2005$} & $C_{5}: y=0.8418 x+1.8087 ; R^{2}=0.3797$ & \multirow{3}{*}{-5.45} & \multirow{3}{*}{-19.95} & \multirow{3}{*}{-22.18} & \multirow{3}{*}{15.84} \\
\hline & & $C_{10}: y=0.7554 x+2.5692 ; R^{2}=0.2638$ & & & & \\
\hline & & $C_{15}: y=1,2407 x-2.7212 ; R^{2}=0.7564$ & & & & \\
\hline \multirow{3}{*}{ S3 } & \multirow{3}{*}{$28 / 10 / 2002$} & $C_{5}: y=0,9831 x+0,6616 ; R^{2}=0,9404$ & \multirow{3}{*}{-14.23} & & & \\
\hline & & $C_{10}: y=1,0683 x-0,6191 ; R^{2}=0,9524$ & & -25.12 & -21.60 & -17.16 \\
\hline & & $C_{15}: y=0,9848 x+0,3204 ; R^{2}=0,9186$ & & & & \\
\hline & & $C_{5}: y=1,0923 x-0,8681 ; R^{2}=0,94$ & & & & \\
\hline S4 & $28 / 10 / 2002$ & $C_{10}: y=1,1116 x-1,3356 ; R^{2}=0,9492$ & -6.37 & -15.53 & -10.30 & -7.25 \\
\hline & & $C_{15}: y=1,0227 x-0,2685 ; R^{2}=0,9163$ & & & & \\
\hline & & $C_{5}: y=1,3852 x-4,35 ; R^{2}=0,9665$ & & & & \\
\hline S5 & $10 / 05 / 2004$ & $C_{10}: y=0,954 x+0,7115 ; R^{2}=0,9915$ & -1.88 & 1.69 & 28.47 & -6.49 \\
\hline & & $C_{15}: y=0,9438 x+0,7984 ; R^{2}=0,9894$ & & & & \\
\hline & & $C_{5}: y=1,0567 x-2,7928 ; R^{2}=0,9894$ & & & & \\
\hline S6 A & $15 / 05 / 2004$ & $C_{10}: y=1,1332 x-4,7736 ; R^{2}=0,9679$ & 30.81 & 83.96 & 110.98 & 94.97 \\
\hline & & $C_{15}: y=1,078 x-3,4839 ; R^{2}=0,9486$ & & & & \\
\hline & & $C_{5}: y=0,6028 x+6,8452 ; R^{2}=0,3515$ & & & & \\
\hline S6 B & $16 / 08 / 2004$ & $C_{10}: y=-0,0693 x+20,269 ; R^{2}=0,0029$ & 55.22 & 97.83 & 123.89 & 125.42 \\
\hline & & $C_{15}: y=-0,3659 x+26,592 ; R^{2}=0,1363$ & & & & \\
\hline & & $C_{5}: y=1,1488 x-3,8955 ; R^{2}=0,9189$ & & & & \\
\hline S7 A & $22 / 09 / 2005$ & $C_{10}: y=1,0032 x-1,2942 ; R^{2}=0,8203$ & 40.27 & 69.81 & 71.17 & 65.54 \\
\hline & & $C_{15}: y=1,1275 x-3,3363 ; R^{2}=0,9275$ & & & & \\
\hline & & $C_{5}: y=0,5683 x+5,9323 ; R^{2}=0,8663$ & & & & \\
\hline S7 B & $22 / 04 / 2006$ & $C_{10}: y=0,9635 x-0,28 ; R^{2}=0,925$ & 16.13 & -21.37 & 32.49 & 36.85 \\
\hline & & $C_{15}: y=1,0345 x-1,1833 ; R^{2}=0,9594$ & & & & \\
\hline & & $C_{5}: y=0,699 x+5,2275 ; R^{2}=0,9899$ & & & & \\
\hline S7 C & $03 / 07 / 2006$ & $C_{10}: y=0,8556 x+2,0696 ; R^{2}=0,9413$ & 36.29 & 66.15 & 61.57 & 62.03 \\
\hline & & $C_{15}: y=0,9345 x+0,368 ; R^{2}=0,9654$ & & & & \\
\hline
\end{tabular}

suitable values for use in the calculation: $\mathrm{C}_{5}$ for $\mathrm{S} 2 \mathrm{~A}, \mathrm{~T}_{\mathrm{ws}}$ for $\mathrm{S} 2 \mathrm{~B}$, and $C_{10}$ and $C_{15}$ for $\mathrm{S} 2 \mathrm{C}$.

In partially protected conditions $(\mathrm{S} 3, \mathrm{~S} 4)$, the $T_{\mathrm{ws}}$ were the nearest to $T_{d}$, and in the ADD model, the lowest deviation was obtained with $T_{\text {ws }}$. However, for S3, the most suitable data for the estimation of the developmental time of $P$. terraenovae were obtained using $C_{5}$. For the others species, the use of $C_{5}$ data resulted in the most significant ADD deviation.

In protected conditions, $T_{\text {ws }}$ were the most appropriated data to use for all sites, except for S5 where a correlation based on 5 days gave a similar estimate for C. vicina and $P$. terraenovae. However, for $\mathrm{S} 5$, the differences with $T_{\mathrm{ws}}$ were negligible when compared with $T_{\text {est }_{10}}$ and $T_{\text {est }_{15}}$. For
S6 (A and B), $T_{\mathrm{ws}}$ was the closest and the deviation could be considered as significant in comparison with the ADD obtained by $T_{d}$. This difference was very marked in the temperature obtained by all the linear regressions.

For S7, none of linear regressions could be applied for the three periods of study; $T_{\mathrm{ws}}$ gave the best result for all species and in all cases. For S7A and S7C, the results obtained with linear regressions were very close. For S7B, the situation was less homogeneous; temperatures were overestimated with $C_{5}$ for all species and with $C_{15}$ for $P$. terraenovae.

Finally, for all the species and temperatures considered, the higher the developmental threshold is, the greater the deviation became. Therefore, for a species with a low developmental threshold, for example, C. vicina, the PMI was 


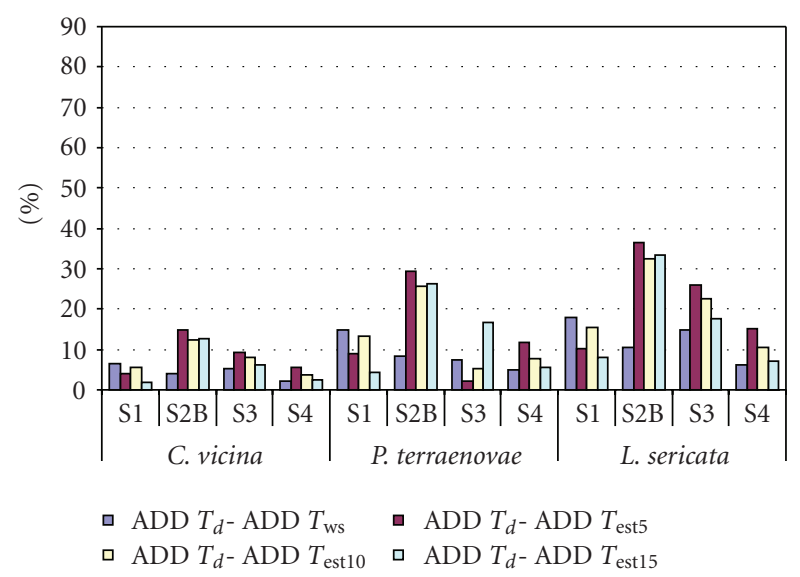

Figure 5: Differences between ADD $T_{d}$ and ADD values using $T_{\text {ws }}$ and correlations compared to ADD $T_{d}$, expressed as percentages $\left.\left(\left[\mathrm{ADDx}-\mathrm{ADD} T_{d}\right) / \mathrm{ADD} T_{d}\right] \times 100\right)$ for data registered in autumn.

closer to reality compared to a species with a higher threshold. Moreover, whatever the origin of temperatures (whether from weather station or estimated by linear regression), there existed a difference (positive or negative) with temperatures recorded on the site by the data loggers.

\section{Discussion}

In forensic entomology technique, one solution to obtaining an estimate of the temperature data that the body might have been exposed to would be the use of a mathematical tool to obtain an estimate based on temperatures recorded at the site post body discovery and weather station temperature data. However, neither temperatures from linear correlations nor weather station data could provide a truly accurate representation of temperatures experienced at a crime scene.

4.1. Effect of Linear Regression. If we compare all of the results obtained for the three different time intervals ( 5 , 10 , and 15 days) for the linear regressions used in the 12 "cases", none of these were more suitable than the others for describing the situation recorded by data loggers. Moreover, consequences on the time duration were not standardized and could increase the deviation significantly. For example, for S2B and Lucilia sericata, development time deviation obtained with linear regressions was three times greater than when using weather station. For S6A, development time deviation with $T_{\text {est } 10}$ reached $82.2 \%$ of the total development time obtained with $T_{d}$ for the same species whereas this deviation was $30.3 \%$ with $T_{\text {ws. }}$. Thus, a positive deviation from temperatures registered by data loggers caused an overestimation of the local temperatures and led to reduce estimate of the length of time for insect development. A negative deviation caused an underestimation of the local temperatures and thus led to increase estimate of the length of time for insect development.

Furthermore, in ADD calculation, insect time developments could be affected when ambient temperature is closed to their theoretical development threshold $[4,18,20]$. This is especially true when temperatures estimated by linear regression are lower than the threshold whereas temperatures recorder on the site are upper.

4.2. Effect of External Parameters. Within the same site, it was difficult to estimate the impact of the time of year on the method to use. For example, for S2, three times of year were selected and the linear regression for 5 days was more representative in June whereas $T_{\text {ws }}$ was the most appropriate for October and $C_{10}$ or $C_{15}$ in March. This situation, at similar times of year, was not the same at sites S6 and S7. Here, $T_{\text {ws }}$ was the most suitable value to use in calculations.

Additionally, neither the correlation data nor the data from Méteo France were linked to the distance between the site and the weather station locations. At site S1, the distance from the station was 30 meters and the best result was obtained using $C_{15}$. For more distant stations (12.2 kilometers for S6 and S7) $T_{\text {ws }}$ were the most suitable data to use.

Regarding the three different types of location (Figure 1), it appeared that $T_{\mathrm{ws}}$ was more accurate for describing the situation for partially protected and protected exposures (except for S5 which had a small difference between $T_{\mathrm{ws}}$ and $\mathrm{C}_{5}$ ). For S1 and S2 (in exposed conditions), $T_{\mathrm{ws}}$ values were not the most suitable. This could be explained by the Météo France protocol whereby ambient temperatures are recorded under sheltered conditions.

4.3. PMI Estimation. The forensic entomologist has to use the most reliable data to provide an accurate PMI. At first glance, a statistical model based on correlations would appear to be a logical and useful method. However, the situation is more complex and depends on many external factors which are difficult to quantify. Regression (i.e., linear), sometime used in casework, is useful but there is risk of obtaining a significant deviation from the temperatures actually experienced at the crime scene. Correlations are obtained with data recorded after the body has been discovered and insect development has already occurred. Rain, direct sun exposure on the corpse and the state of the vegetation in the vicinity are some parameters which may directly affect the local temperature experienced by the necrophagous insects [5]. Therefore, care needs to be taken when using estimates obtained from linear regression calculations for temperatures at a crime scene and climatic variations during that occurred during the period of the body being present should be considered is possible.

Regarding this study and the extent of the meteorological station network available in France, the department of forensic entomology from IRCGN will continue to use data from Météo France directly in its forensic casework. Despite the fact that weather station data are likely to be different from conditions experienced at the crime scene, they should be considered, by default, as the most ideal data to use for PMI estimations, bearing in mind the possibility of any deviations. The risk of any deviations is considered to be acceptable for the purposes of forensic entomology as long as they are taken into account when providing PMI estimations and an appropriate range is given. 
At least, it is necessary to realize that this study was performed with Marchenko data (ADD model). However, numerous authors displayed disparities in the threshold value for a same species depending, for example, on protocols of the study or the geographical strain origin [21-23]. These different parameters affect the postmortem interval calculation.

Thus, a deeper understanding of insect development rates, their physiological activity close to the developmental threshold, and the succession mechanisms of necrophagous insects may be a better way of improving the accuracy of PMI estimates in forensic entomology.

\section{Acknowledgments}

The authors are very grateful to Bernard Chauvet, Fabrice Lefèbvre, and Jean-Bernard Myskowiak for their great help to carry out these experiments. They thanks also Gérard Mayençon from Météo France for his availability and his technical advises. Special thanks to Andrew Hart for his precious help.

\section{References}

[1] J. H. Byrd and J. L. Castner, Forensic Entomology: The Utility of Arthropods in Legal Investigations, CRC Press, Boca Raton, Fla, USA, 2001.

[2] J. Amendt, C. P. Campobasso, E. Gaudry, C. Reiter, H. N. LeBlanc, and M. J. R. Hall, "Best practice in forensic entomology-standards and guidelines," International Journal of Legal Medicine, vol. 121, no. 2, pp. 90-104, 2007.

[3] K. J. V. Smith, A Manual of Forensic Entomology, Cornell University Press, London, UK, 1986.

[4] M. Hall and S. Donovan, "Forensic entomology: what can maggots tell us about murders?" Biologist, vol. 48, no. 6, pp. 249-253, 2001.

[5] E. P. Catts, "Problems in estimating the postmortem interval in death investigation," Journal of Agricultural Entomology, vol. 9, no. 4, pp. 245-255, 1992.

[6] B. Greenberg and J. C. Kunich, Entomology and the Law: Flies as Forensic Indicators, Cambridge University Press, Cambridge, UK, 2002.

[7] D. E. Gennard, Forensic Entomology: An Introduction, John Wiley \& Sons, Chichester, UK, 2007.

[8] A. S. Kamal, "Comparative study of thirteen species of sarcosaprophagous Calliphoridae and Sarcophagidae (Diptera)," Annals of the Entomological Society of America, vol. 51, pp. 261$271,1958$.

[9] J. B. Myskowiak and C. Doums, "Effects of refrigeration on the biometry and development of Protophormia terraenovae (Robineau-Desvoidy) (Diptera : Calliphoridae) and its consequences in estimating postmortem interval in forensic investigations," Forensic Science International, vol. 125, pp. 254-261, 2002.

[10] M. Grassberger and C. Frank, "Initial study of arthropod succession on pig carrion in a central European urban habitat," Journal of Medical Entomology, vol. 41, no. 3, pp. 511-523, 2004.

[11] E. Gaudry, J.-B. Myskowiak, B. Chauvet, T. Pasquerault, F. Lefebvre, and Y. Malgorn, "Activity of the forensic entomology department of the French Gendarmerie," Forensic Science International, vol. 120, no. 1-2, pp. 68-71, 2001.
[12] T. Pasquerault, B. Vincent, L. Dourel, B. Chauvet, and E. Gaudry, "Los muestreos entomologicos: de la escena del crimen a la peritacion," Ciencia Forense, vol. 8, pp. 39-55, 2006.

[13] N. H. Haskell and R. E. Williams, "Collection of entomological evidence at the death scene," in Entomology \& Death: A Procedural Guide, E. P. Catts and N. H. Haskell, Eds., pp. 8297, Joyce's Print Shop, Clemson, SC, USA, 1990.

[14] L. M. Goff, A fly for the prosecution: how insect evidence helps solve crimes, Harvard University Press, Cambridge, UK, 2000.

[15] L. Bourguignon, M. Gosselin, Y. Braet, F. Hubrecht, and J. Karapetian, "Forensic entomology and short-term PMI estimation: a case report," Belgian Journal of Entomology, vol. 8, pp. 17-25, 2006.

[16] F. Introna and C. P. Campobasso, Entomologia forense: il ruolo dei ditteri nelle indagini medico legali, Essebiemme Edizioni, Noceto, Italy, 1998.

[17] C. Wyss and D. Cherix, Traité d'entomologie forensique: les insectes sur la scène de crime, Presses Polytechniques et Universitaires Romandes, Lausanne, Switzerland, 2006.

[18] M. S. Archer, "The effect of time after body discovery on the accuracy of retrospective weather station ambient temperature corrections in forensic entomology," Journal of Forensic Sciences, vol. 49, no. 3, pp. 553-559, 2004.

[19] M. I. Marchenko, "Medicolegal relevance of cadaver entomofauna for the determination of the time of death," Forensic Science International, vol. 120, no. 1-2, pp. 89-109, 2001.

[20] P. D. Nabity, L. G. Higley, and T. M. Heng-Moss, "Effects of temperature on development of Phormia regina (Diptera: Calliphoridae) and use of developmental data in determining time intervals in forensic entomology," Journal of Medical Entomology, vol. 43, no. 6, pp. 1276-1286, 2006.

[21] C. S. Richards and M. H. Villet, "Factors affecting accuracy and precision of thermal summation models of insect development used to estimate post-mortem intervals," International Journal of Legal Medicine, vol. 122, no. 5, pp. 401-408, 2008.

[22] G. S. Anderson, "Minimum and maximum development rates of some forensically important calliporidae (Diptera)," Journal of Forensic Science, vol. 45, pp. 824-832, 2000.

[23] C. S. Richard and M. H. Villet, "Data quality in thermal summation development models for forensically important blowflies," Medical and Veterinary Entomology, vol. 23, pp. 269-276, 2009. 

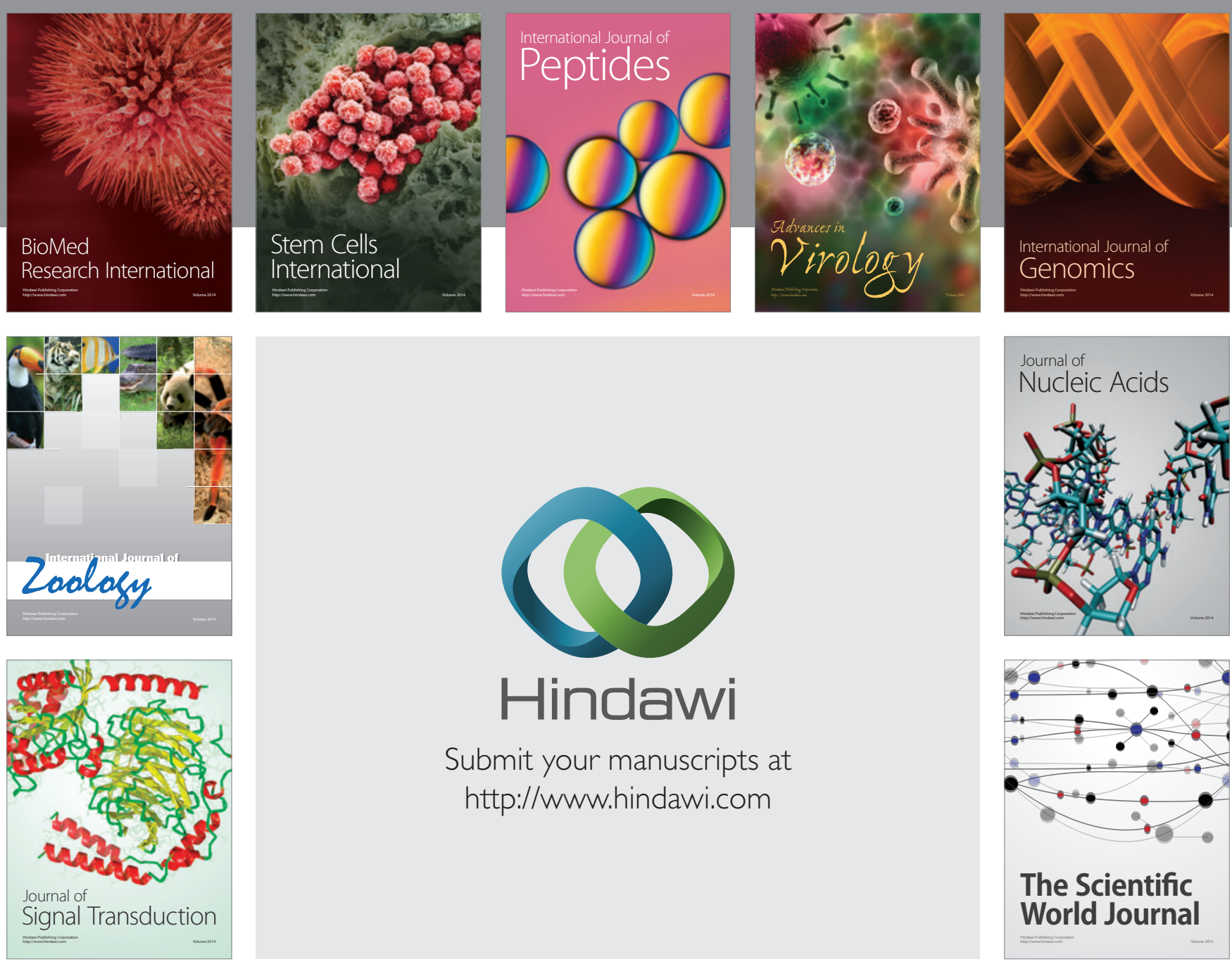

Submit your manuscripts at

http://www.hindawi.com
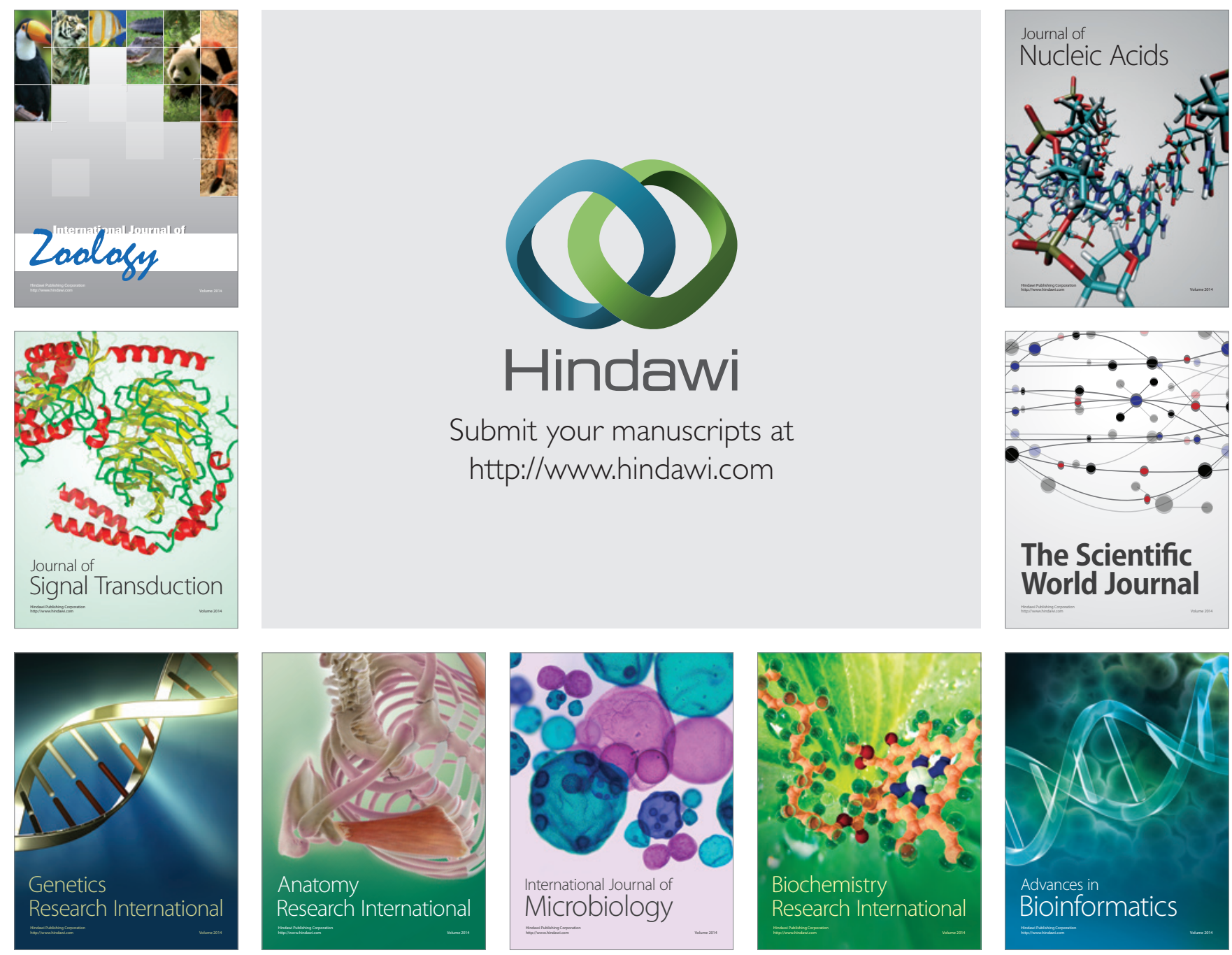

The Scientific World Journal
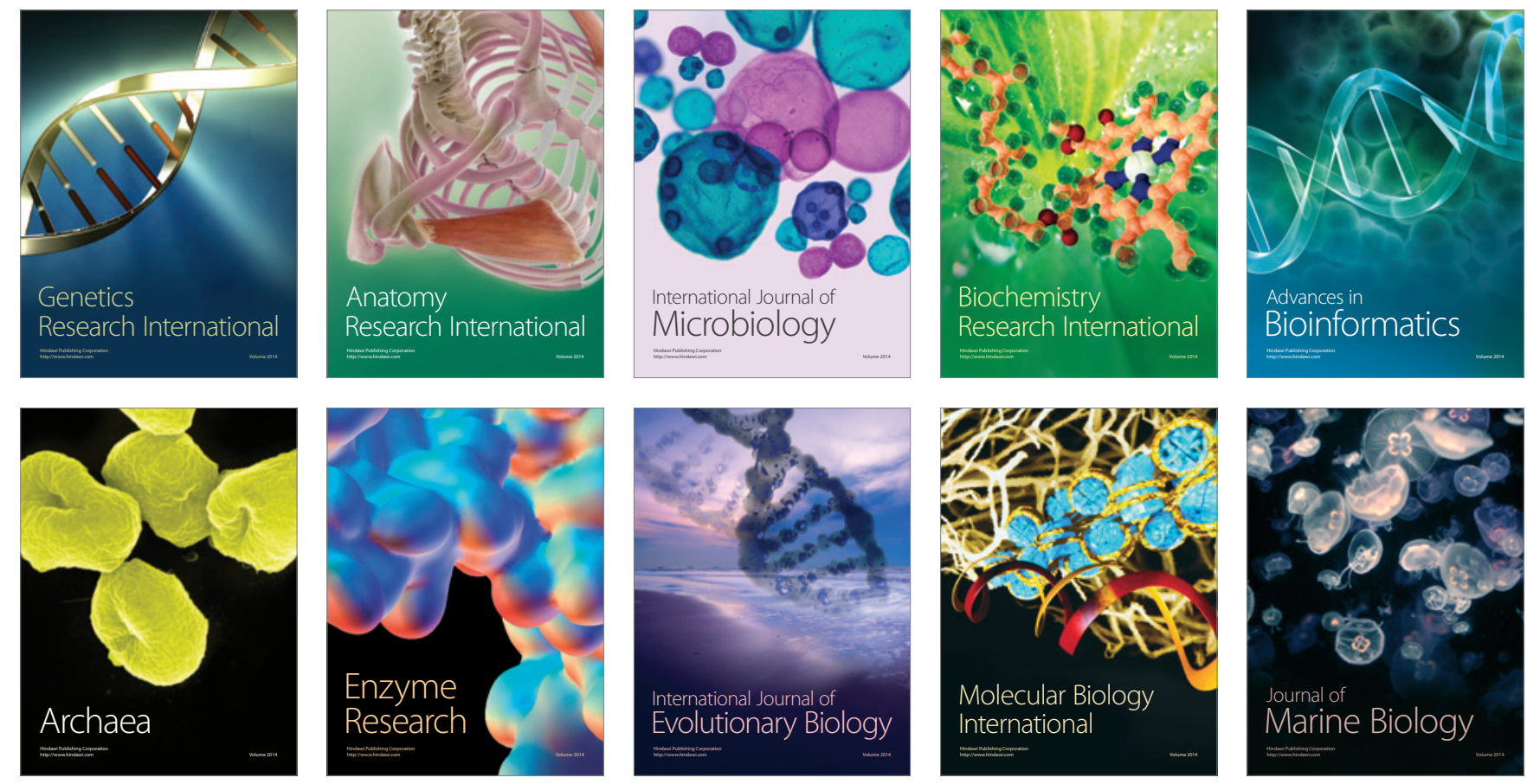